\title{
Article \\ Adequacy of Near Real-Time Satellite Precipitation Products in Driving Flood Discharge Simulation in the Fuji River Basin, Japan
}

\author{
Li Zhou ${ }^{1,2, *(\mathbb{D})}$, Mohamed Rasmy ${ }^{2}$, Kuniyoshi Takeuchi ${ }^{3} \mathbb{D}$, Toshio Koike ${ }^{2}$, Hemakanth Selvarajah ${ }^{2,4}$ \\ and Tianqi Ao ${ }^{1, *}$
}

Citation: Zhou, L.; Rasmy, M.; Takeuchi, K.; Koike, T.; Selvarajah, H.; Ao, T. Adequacy of Near Real-Time Satellite Precipitation Products in Driving Flood Discharge Simulation in the Fuji River Basin, Japan. Appl. Sci. 2021, 11, 1087. https:// doi.org/10.3390/app11031087

Received: 22 December 2020

Accepted: 21 January 2021

Published: 25 January 2021

Publisher's Note: MDPI stays neutral with regard to jurisdictional claims in published maps and institutional affiliations.

Copyright: (c) 2021 by the authors. Licensee MDPI, Basel, Switzerland. This article is an open access article distributed under the terms and conditions of the Creative Commons Attribution (CC BY) license (https:// creativecommons.org/licenses/by/ $4.0 /)$.
1 State Key Laboratory of Hydraulics and Mountain River Engineering, College of Water Resource \& Hydropower, Sichuan University, No. 24 South Section 1, Yihuan Road, Chengdu 610065, China

2 International Centre for Water Hazard and Risk Management under the Auspices of UNESCO (ICHARM), Public Works Research Institute, 1-6 Minamihara, Tsukuba, Ibaraki 305-8516, Japan; rasmy@icharm.org (M.R.); koike@icharm.org (T.K.); shemakanth@gmail.com (H.S.)

3 Interdisciplinary Centre for River Basin Environment, University of Yamanashi, 4 Chome-4-37 Takeda, Kofu, Yamanashi 400-8510, Japan; takeuchi@yamanashi.ac.jp

4 National Graduate Institute for Policy Studies (GRIPS), 7 Chome-22-1 Roppongi, Minato City, Tokyo 106-0032, Japan

* Correspondence: zhouli.scu@gmail.com (L.Z.); aotianqi@scu.edu.cn (T.A.)

Abstract: Flood management is an important topic worldwide. Precipitation is the most crucial factor in reducing flood-related risks and damages. However, its adequate quality and sufficient quantity are not met in many parts of the world. Currently, near real-time satellite precipitation products (NRT SPPs) have great potential to supplement the gauge rainfall. However, NRT SPPs have several biases that require corrections before application. As a result, this study investigated two statistical bias correction methods with different parameters for the NRT SPPs and evaluated the adequacy of its application in the Fuji River basin. We employed Global Satellite Mapping of Precipitation (GSMaP)-NRT and Integrated Multi-satellitE Retrievals for GPM (IMERG)-Early for NRT SPPs as well as BTOP model (Block-wise use of the TOPMODEL (Topographic-based hydrologic model)) for flood runoff simulation. The results showed that the corrected SPPs by the 10-day ratio based bias correction method are consistent with the gauge data at the watershed scale. Compared with the original SPPs, the corrected SPPs improved the flood discharge simulation considerably. GSMaP-NRT and IMERG-Early have the potential for hourly river-flow simulation on a basin or large scale after bias correction. These findings can provide references for the applications of NRT SPPS in other basins for flood monitoring and early warning applications. It is necessary to investigate the impact of number of ground observation and their distribution patterns on bias correction and hydrological simulation efficiency, which is the future direction of this study.

Keywords: NRT SPPs; GSMaP; IMERG; bias correction; BTOP model; flood discharge simulation

\section{Introduction}

Flooding is an inevitable natural hazard, but it is also a valuable water resource. How to manage and utilize floodwater efficiently has always been a hot and challenging spot in global research. As a non-structural measure, flood forecasting helps to control and take advantage of the excess water effectively. Precipitation data are one of the most important boundary conditions in flood forecasting models [1]. However, it also brings uncertainty to flood forecasting [2], particularly in ungauged or poorly gauged basins. A previous study indicated that $70-80 \%$ of the uncertainties of hydrological simulations are due to the uncertainties in precipitation data [3]. Therefore, accurate and reliable precipitation data are crucial for hydrological forecasting and water resources management. 
For a long time, hydrologists have mainly relied on a network of ground observation stations to obtain precipitation information. If only ground observations are used, one observation often represents actual rainfall in the range of hundreds, thousands, or even tens of thousands of square kilometers due to poor ground observation network. However, the actual precipitation is a weather process with significant variability in different time and space scales [4]. Insufficient spatial representation of the ground networks often leads to errors in estimating the spatial and temporal distribution of precipitation, which has become a primary source of uncertainty in hydrological simulations [5].

The satellite-based quantitative precipitation estimation technology has made significant progress in the past decades. The observation resolution and estimation accuracy have been continuously improving and have gradually become an essential tool for realtime rainfall monitoring for disaster early warning on global, regional, and catchment scales. It provides beneficial information on rainfall for hydrological studies in data-sparse basins [6,7]. Many organizations and institutions around the world have released satellite precipitation products (SPPs) with various spatial and temporal resolution such as Tropical Rainfall Measuring Mission (TRMM) [8], Precipitation Estimation from Remotely Sensed Information using Artificial Neural Networks (PERSIAN) [9], Climate Prediction Center Morphing Technique (CMORPH) [10], Global Satellite Mapping of Precipitation (GSMaP) [11,12], and Integrated Multi-satellite Retrievals for Global Precipitation Measurement (GPM IMERG) [13]. Now the near-real-time (NRT) satellite precipitation products (SPPs) have a high spatial and temporal resolution. As they are available at a shorter latency time $(\sim 4 \mathrm{~h})$, they have a great potential to be used for near real-time extreme weather monitoring, flood early warning, and flood impact assessments at both local and global scales [14-16]. Therefore, NRT SPPs are a useful alternative data source in the disaster warning and management of floods and droughts, especially in ungauged basins [17].

However, there is still a gap between observed precipitation and SPPs, especially the NRT SPPs $[18,19]$. The main reason is that the accuracy of SPPs is affected by various factors, such as sampling uncertainty, indirect observation errors, and inversion algorithms [20]. Moreover, the characteristics of these factors will change with precipitation mechanisms, climatic zones, seasons, altitude, and terrain conditions. Although many studies focused on NRT SPPs [21-23], the applications of NRT SPPs in simulating flood discharge are relatively few due to their low accuracy since they are accompanied by large errors, especially in the range of local and catchment scale [24,25]. The main reason is that the NRT products are prepared very quickly with shorter latency time by integrating limited available microwave observations from multiple satellites, and data unavailability regions are filled by interpolation or morphing techniques based on cloud movements from infrared (IR) data. Furthermore, other factors, such as indirect observation errors and inversion algorithms, also play an essential role in determining accuracy [20]. Therefore, it is essential to introduce bias correction methods to improve NRT SPPs before their practical application [26]. As a result, several previous studies focused on reducing biases or deviations in NRT SPPs with different methods such as mean factor correction method [27,28], quantile mapping approach [29,30], Bayesian method [31], multiplicative bias correction [32], and ratio bias correction method [32,33]. Moreover, some new techniques like merging soil moisture with SPPs were introduced [34]. At the same time, the rainfall retrieval algorithms are also keeping updated to improve the rainfall estimation by introducing several changes for topographical correction [35], noise reduction [36], and precipitation type [37]. Therefore, scientific studies on the evaluation of NRT SPPs should be continued to assess their capability, identify biases, use bias correction methods to enhance their applicability in real-time monitoring and early warning application, and carry out disaster risk reduction and damage assessments in data poor or ungauged basins.

Accordingly, this paper focused on enhancing the applicability of NRT SPPs $(\sim 4 \mathrm{~h}$ latency) in driving the hydrological model for flood discharge simulation by identifying the proper method to correct NRT SPPs and evaluating bias correction and flood simulation performance. In order to fulfill the objectives above, this study investigated the performance 
of two statistical bias correction methods for NRT SPPs and their impacts on the accuracy of flood discharge simulation with the Block-wise use of the TOPMODEL (Topographic-based hydrologic model) (BTOP) model in a data-rich river basin, the Fuji River basin. GSMaPNRT and IMERG-Early were selected as NRT SPPs. Two bias correction methods (simple multiplicative bias correction and ratio bias correction) with two bias factors (10-day and monthly) were employed to correct the NRT SPPs on different temporal scales. In addition, comprehensive evaluation criteria are used for evaluating both original and corrected NRT SPPs. Finally, the BTOP model was developed to simulate flood discharges at hourly steps with five types of precipitation inputs for each data source.

\section{Study Area and Data}

\subsection{Study Area}

As a study basin, the Fuji River basin was selected as it is a well-gauged basin, i.e., 28 ground observation stations in a $3570 \mathrm{~km}^{2}$ area (the average observation density: $127.5 \mathrm{~km}^{2} /$ station). Although it is beyond this study's scope, this basin can eventually serve to identify the effect of ground observation density on the accuracy of SPPs' bias correction.

The Fuji River, located in the middle of Honshu Island, Japan, is one of the steepest rivers in Japan (Figure 1). The river comes from the Nokogiri Mountains with an altitude of about $2600 \mathrm{~m}$ in the northwest of Yamanashi Prefecture. It runs from the mountainous region to the Kofu (the capital of Yamanashi Prefecture) plain and then runs through the mountainous region before discharging out into the Pacific Ocean. The mainstream length is about $128 \mathrm{~km}$. Summer is hot and humid, and winter is cold, with an average temperature of $26^{\circ} \mathrm{C}$ and $3{ }^{\circ} \mathrm{C}$, respectively. Furthermore, the mean annual precipitation of the basin and mean annual runoff at Kitamatsuno discharge station are $2100 \mathrm{~mm}$ and $69.2 \mathrm{~m}^{3} / \mathrm{s}$, respectively [38]. The rainy season is from the end of August to the beginning of October, during which typhoons often occur, and the risk of heavy rain is high.

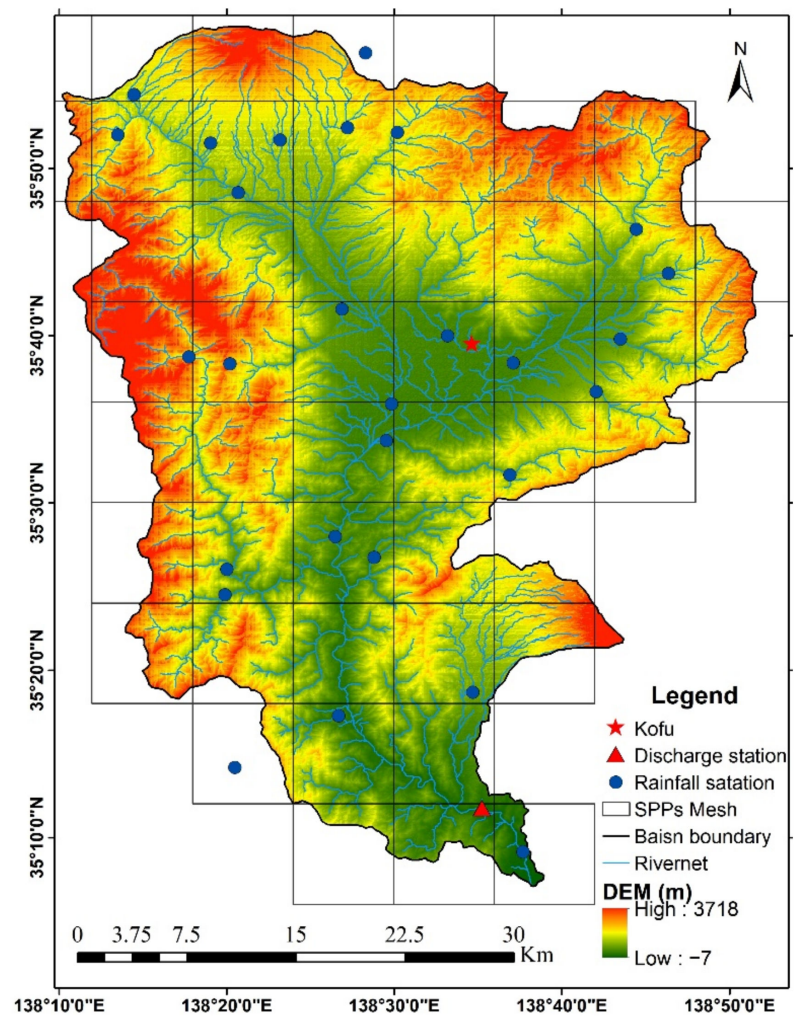

Figure 1. Digital Elevation Model (DEM) and gauge stations in the Fuji River basin. In total, twentyeight rain gauges and forty-seven SPP meshes were involved in the calculation. The capital of Yamanashi Prefecture, Kofu city, is located in the Kofu Basin. 


\subsection{Data}

\subsubsection{Precipitation Data}

(a) Gauge Data

Figure 1 shows the spatial distribution of the 28 rainfall gauge stations. We collected hourly rainfall data during 2002-2011 from Japan Meteorological Agency (JMA) and Ministry of Land, Infrastructure, Transport and Tourism (MLIT). To be consistent with SPPs, the daily gauge rainfall was shifted to Coordinated Universal Time (UTC) while hourly data remain with Japan Standard Time (JST, UTC+9h), as the discharge data are recorded in local time.

\section{(b) GSMaP NRT Data}

GSMaP-NRT hourly data were obtained from the Japan Aerospace Exploration Agency (JAXA). It has a spatial resolution of $0.1^{\circ} \times 0.1^{\circ}$ and $4 \mathrm{~h}$ latency [12]. The GSMaP uses a combined algorithm of microwave (MW) and infrared (IR) data [11]. It adopted the Kalman filter to update the precipitation rate produced by forward propagation of the rainfall which obtained from MW sensors. According to the selected period of gauge rainfall, we employed version 6 of GSMaP-NRT (v6) in this study. The data can be accessed freely after registration on the JAXA GSMaP website [39].

(c) IMERG Early Data

The IMERG products of the National Aeronautics and Space Administration (NASA) is global rainfall product with a temporal resolution of $0.5 \mathrm{~h}$ and a spatial resolution of $0.1^{\circ}$ [13]. TRMM-era (1997-2015) data have been reprocessed using the IMERG algorithm for 2000-present, creating a long-term continuous IMERG data record. There are three types of products (Early, Late, and Final) from NASA. Among them, the IMERG Early Run uses historical climate data for calibration, and the latency is $4 \mathrm{~h}$. In this study, we employed the IMERG Early Run dataset with the same resolution and latency of GSMaP-NRT, which is available on the NASA Goddard Earth Sciences (GES) Data and Information Services Center (DISC) website [40].

It should be noted that all hourly precipitation data are prepared in JST, whereas daily precipitation data are prepared in UTC. Furthermore, we extracted 47 grids of SPPs in the Fuji River basin (Figure 1) to compare with gauge rainfall in the watershed scale.

\subsubsection{Other Model Input Data}

The BTOP model, which is used as a hydrological model in this study, requires a variety of input data such as precipitation, Digital Elevation Model (DEM), land cover, soil type, Normalized Difference Vegetation Index (NDVI), and meteorological data.

DEM was obtained from NASA's Shuttle Radar Topography Mission (SRTM) with an original resolution of 3 arc-seconds [41]. We employed the International GeosphereBiosphere Program (IGBP) map as land cover data with an original resolution of $500 \mathrm{~m}$ [42]. Soil properties of this study area are obtained by using the soil map of the Food and Agriculture Organization (FAO) at the scale of 1:5 million [43]. NDVI came from the National Oceanic and Atmospheric Administration (NOAA) of the United States with an original resolution of 0.05 degree [44]. The Climate Research Unit (CRU) provides meteorological data [45], such as temperature, radiation, humidity, wind speed, and vapor pressure. All the above datasets could be accessed freely on their official website and were resampled to 30 arc-seconds (approximately $1 \mathrm{~km}$ ) for BTOP model simulation. Moreover, the discharge data at the Kitamatsuno station were downloaded from MLIT as the same source with gauge rainfall.

\section{Methodology}

Figure 2 shows the framework of this study. First, prepare the gridded dataset with the Inverse Distance Weighted (IDW) method. Simple multiplicative bias correction (SMBC) and ratio bias correction (RBC) are used to correct NRT SPPs with two time-scale factors. A comprehensive evaluation is then applied to evaluate bias correction's performance at four temporal resolutions (hourly, daily, 10-day, and monthly). After that, the BTOP 
model is driven by five precipitation datasets to simulate the discharge in five flood cases separately. At last, four criteria indicators are chosen for evaluating the hydrological simulation performance. The details of the methodology are described in Sections 3.1-3.3.

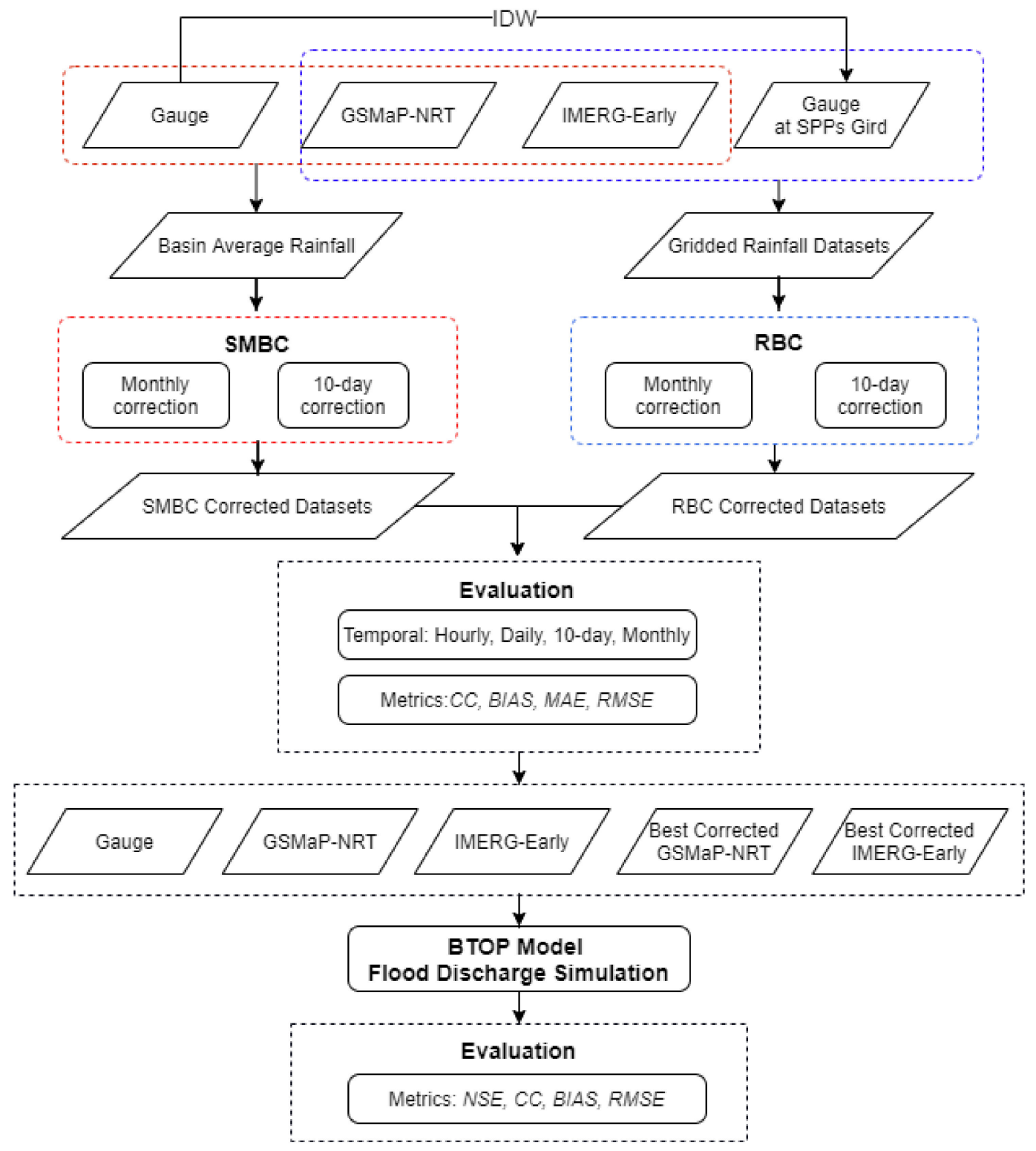

Figure 2. Framework of this study.

\subsection{Bias Correction Methods}

This paper implemented two bias correction methods: simple multiplicative bias correction (SMBC) and ratio bias correction (RBC). As the Fuji River has sufficient rainfall stations, the robust and straightforward bias correction techniques were primarily selected.

\subsubsection{Simple Multiplicative Bias Correction}

The principle of the mean bias correction method is operable and straightforward. It assumes that satellite precipitation and ground observation precipitation have a uniform bias in the entire watershed. It is essentially a globally used standard correction method. However, it ignores the temporal and spatial heterogeneity of precipitation distribution within the watershed. The SMBC considers the time distribution compared to the mean 
bias correction method [46], and the corresponding bias factor is obtained on a month and 10-day basis. Specific methods are shown as Equations (1) and (2).

$$
\begin{gathered}
\text { BiasFactor }\left(T_{t}\right)=P^{S}\left(T_{t}\right) / P^{g}\left(T_{t}\right) \\
P_{\text {corr }}^{S}\left(P_{(x, y)}, T_{i}\right)=P^{S}\left(P_{(x, y)}, T_{i}\right) / \text { BiasFactor }\left(T_{t}\right)
\end{gathered}
$$

where $P^{S}\left(T_{t}\right)$ and $P^{g}\left(T_{t}\right)$ are monthly or 10-day rainfall of SPPs and gauge at watershedscale, respectively. $P^{S}{ }_{c o r r}\left(P_{(x, y)}, T_{i}\right)$ is the bias-corrected precipitation at grid location $(x, y)$ and time $T_{i}$, which $T_{i}$ is in the time series period $T_{t}$.

\subsubsection{Ratio Bias Correction}

Compared to SMBC, the RBC technique considers the distribution of time and space, which can correct the NRT SPPs more reasonably. Moreover, it is simple and easy to implement applicable. It has a wide range of applications in the field of SPPs correction $[32,33]$ and the Inverse Distance Weighted (IDW) was selected as the interpolation method since it has the advantages of simplicity, computational speed, and good performance $[47,48]$. The main calculation steps are presented below:

(1) Interpolation of gauge rainfall at each station $i$ with Inverse Distance Weighted (IDW) technique to create the grid-based rainfall same as SPPs:

$$
\begin{gathered}
D_{i}=\sqrt{\left(x_{j}-x_{i}\right)^{2}+\left(y_{j}-y_{i}\right)^{2}} \\
P_{j}=\sum_{i=1}^{N} \frac{1}{\left(D_{i}\right)^{p}} P_{i} / \sum_{i=1}^{N} \frac{1}{\left(D_{i}\right)^{p}}
\end{gathered}
$$

where $D_{i}$ is the distance between station $i$ and the center of grid $j, P_{i}$ and $P_{j}$ are rainfall at station $i$ and grid $j$, respectively. $p$ is the power of distance, which usually takes the value of $2 . N$ is the number of stations, and we took 3 in this study to avoid possible new biases since the study case has sufficient data.

(2) Calculating the bias factor $f_{j, T}$ for each grid and time period $T$ by dividing the gauge with SPPs:

$$
f_{j, T}=P_{j, T}^{g} / P_{j, T}^{s}
$$

(3) Finally, the bias-corrected rainfall of SPPs equals the multiplication of bias factor and SPPs at hourly and daily steps within different $T$ (monthly and 10-day):

$$
P_{j, t}^{R B C}=f_{j, T} * P_{j, t}^{s}
$$

\subsection{Evaluation Criteria}

This study employed quantitative evaluation criteria to evaluate both SPPs and simulated discharge based on the observation data. The selected indicators were the correlation coefficient (CC), bias (BIAS), mean absolute error (MAE), root mean square error (RMSE), and Nash-Sutcliffe Efficiency (NSE) [Equations (7)-(11)]. In this study, the evaluation of precipitation was calculated in the basin-scale.

$$
\begin{gathered}
C C=\frac{\sum_{i=1}^{n}\left(X_{i}^{o}-\overline{X^{o}}\right)\left(X_{i}^{s}-\overline{X^{s}}\right)}{\sqrt{\sum_{i=1}^{n}\left(X_{i}^{o}-\overline{X^{o}}\right)^{2}} \sqrt{\sum_{i=1}^{n}\left(X_{i}^{s}-\overline{X^{s}}\right)^{2}}} \\
B I A S=\frac{\sum_{i=1}^{n}\left(X_{i}^{s}-X_{i}^{o}\right)}{n} \\
M A E=\frac{\sum_{i=1}^{n}\left|X_{i}^{s}-X_{i}^{o}\right|}{n}
\end{gathered}
$$




$$
\begin{aligned}
& \text { RMSE }=\sqrt{\frac{\sum_{i=1}^{n}\left(X_{i}^{S}-X_{i}^{o}\right)^{2}}{n}} \\
& N S E=1-\frac{\sum_{i=1}^{n}\left(X_{i}^{S}-X_{i}^{O}\right)^{2}}{\sum_{i=1}^{n}\left(X_{i}^{O}-\bar{X}_{i}^{O}\right)^{2}}
\end{aligned}
$$

where $X^{O}$ is observed data (precipitation or discharge), $X^{S}$ is simulated data (original and bias-corrected SPPs or simulated discharge), $i$ is the number of gauge stations or time series of runoff, $n$ is time steps in the evaluation period.

\subsection{Hydrological Model}

As a rainfall-runoff simulation model, the BTOP model was selected as it is a semiphysically based distributed hydrological model with only five parameters to be calibrated. That is crucial for applying it to the majority of poorly measured basins in the world. It is applicable to small to large basins with slopes that can form streamlines. The BTOP model was first developed in 1999 at the University of Yamanashi [49-52]. The idea was to develop a robust and straightforward hydrological model to simulate runoff based on TOPMODEL [53] by extending it to large basins. After years of continuous development, the BTOP model has been applied in nearly 2300 watersheds worldwide [54,55]. It can be used for multi-purpose such as rainfall-runoff simulation, flood forecasting, and pollutant migration $[56,57]$.

The BTOP model was applied to simulate discharge at Kitamatsuno, catchment area $3331 \mathrm{~km}^{2}$, and $11.6 \mathrm{~km}$ from the Fuji River's estuary. Spatially distributed potential evapotranspiration was calculated by using the Shuttle Worth-Wallace (S-W) model [58]. We selected five cases to simulate flood discharge (i.e., July 2002, August 2003, October 2004, July 2007, and October 2009) as they received the most massive monthly cumulative rainfall of each year and there is almost no precipitation at the beginning of the month, and the discharge was at a low flow stage. October 2004 with gauge rainfall was used for calibration as it received the most extensive monthly rainfall from 2002 to 2011. Then we used five types of precipitation datasets (Gauge, GSMaP-NRT, IMERG-Early, and best bias-corrected SPPs for each) as forcing data for BTOP to simulate flood discharge in all cases.

\section{Results and Discussion}

\subsection{Evaluation of SPPS}

\subsubsection{General Evaluation}

GSMaP-NRT and IMERG-Early (hereafter referred to GSMaP and IMERG, respectively) data and the rain gauge data were compared at the watershed scale at hourly, daily, 10-daily, and monthly temporal scales. To be consistent with the period of the flood simulation, the hourly data were calculated within the case period. In contrast, others employed the data from 2002 to 2011 for a comprehensive evaluation with enough samples.

Figure 3 shows the scatterplots and regression curve of NRT SPPs and gauge rainfall. Based on the regression curve, SPPs underestimated the rainfall at all temporal scales except monthly GSMaP, which performed best with a CC of 0.84 among all temporal scales. Generally, the correlation improved as the temporal scale increased [22]. Moreover, it is evident that there are more dots on the upper left side than the lower right side when hourly rainfall $>5 \mathrm{~mm}$, daily rainfall $>25 \mathrm{~mm}, 10$-day rainfall $>50 \mathrm{~mm}$, and monthly rainfall $>100 \mathrm{~mm}$. It can be concluded that GSMaP and IMERG generally underestimate the extreme precipitation. 


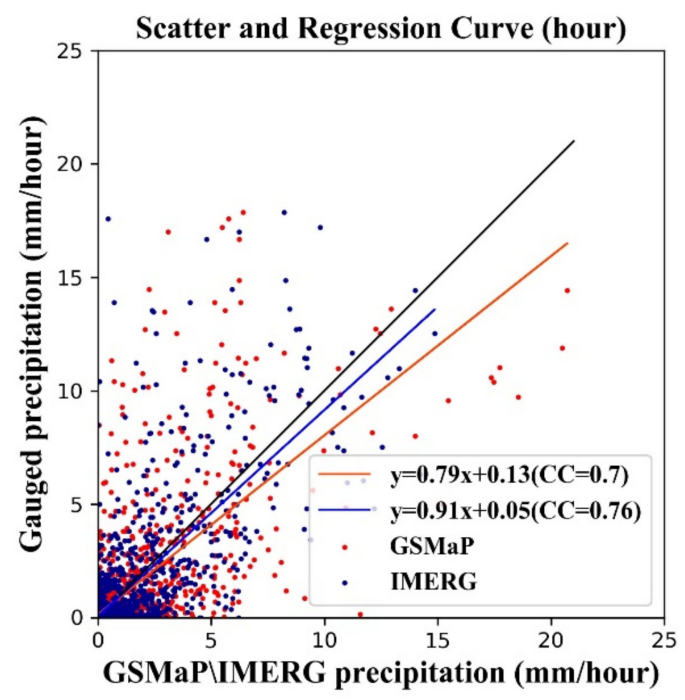

(a)

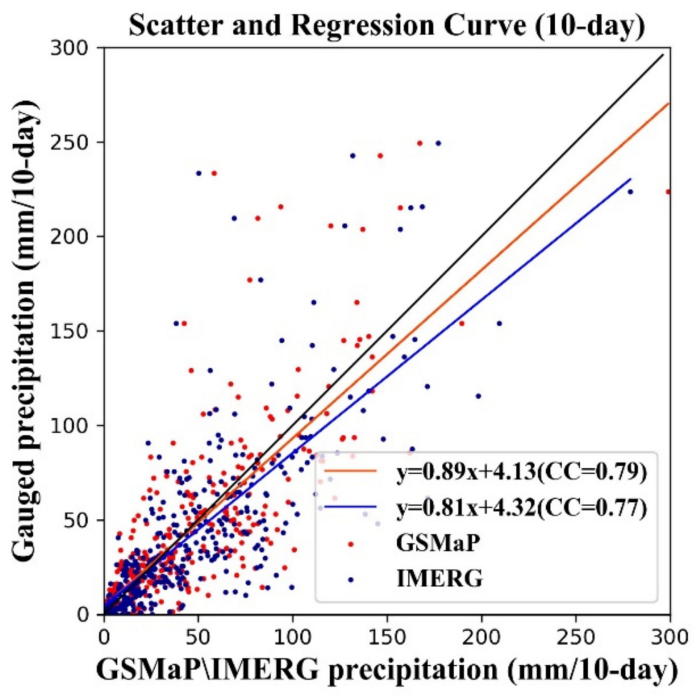

(c)

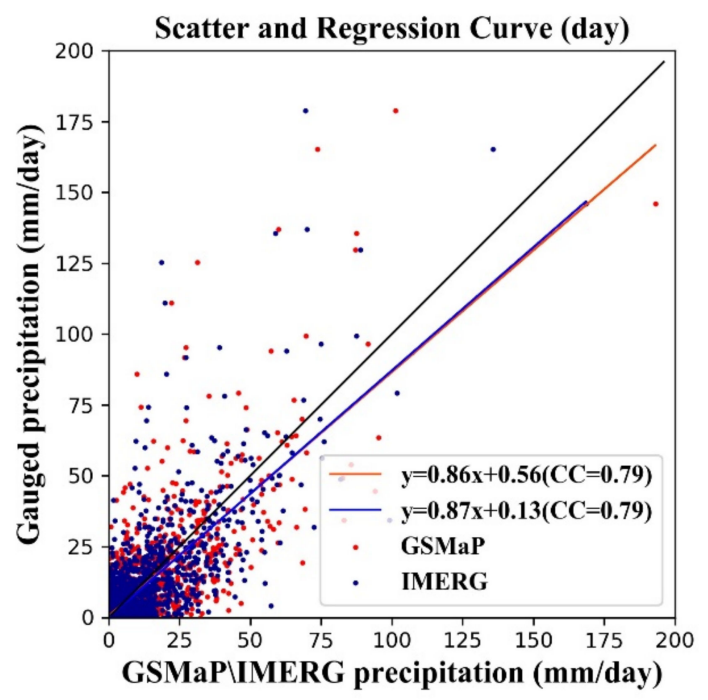

(b)

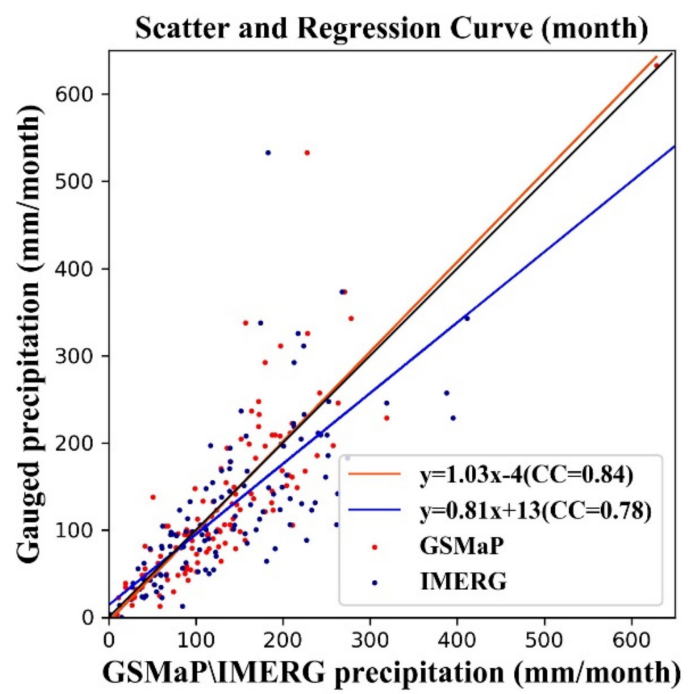

(d)

Figure 3. Scatterplots and regression lines from the original Satellite Precipitation Products (SPPs) and gauges with different temporal scales. (a) hourly, (b) daily, (c) 10-day, (d) monthly. Blue lines and dots denote Integrated Multi-satellite Retrievals (IMERG) Early data, while red lines and dots represent Global Satellite Mapping of Precipitation-Near Real Time (GSMaP-NRT) data, and the black line is the equal line.

Table 1 shows the evaluation results for both original and bias-corrected SPPs more comprehensively. All evaluation metrics were calculated for two bias correction techniques (SMC, RBC) with two bias factors (monthly and 10-day) at all temporal scales. Overall, the SPPs corrected by the 10-day bias factor improved significantly. RBC with a 10-day bias factor was the best correction method among others as all metrics had been significantly improved. In particular, BIAS and CC almost reached the optimal value 0 and 1 after correction. From the aspect of $M A E$ and RMSE, there is little difference on the time scale of hourly and daily no matter which correction method and factor we chose. In addition, on the temporal scale of 10-day and month, both SMBC and RBC performed well only with the corresponding bias factor. 
Table 1. Evaluation criteria for the NRT-SPPs over the Fuji River basin of various temporal scales. The bold values represent the highest recorded performance for each SPPs at each temporal scale.

\begin{tabular}{|c|c|c|c|c|c|c|c|c|c|c|c|}
\hline \multirow{3}{*}{ Metrics } & \multirow{3}{*}{$\begin{array}{l}\text { Time } \\
\text { Scale }\end{array}$} & \multicolumn{5}{|c|}{ GSMaP-NRT } & \multicolumn{5}{|c|}{ IMERG Early } \\
\hline & & \multirow[b]{2}{*}{ Original } & \multicolumn{2}{|c|}{ SMBC } & \multicolumn{2}{|c|}{ RBC } & \multirow[b]{2}{*}{ Original } & \multicolumn{2}{|c|}{ SMBC } & \multicolumn{2}{|c|}{ RBC } \\
\hline & & & $\begin{array}{l}\text { Month } \\
\text { Factor }\end{array}$ & $\begin{array}{l}\text { 10-Day } \\
\text { Factor }\end{array}$ & $\begin{array}{l}\text { Month } \\
\text { Factor }\end{array}$ & $\begin{array}{l}\text { 10-Day } \\
\text { Factor }\end{array}$ & & $\begin{array}{l}\text { Month } \\
\text { Factor }\end{array}$ & $\begin{array}{c}\text { 10-Day } \\
\text { Factor }\end{array}$ & $\begin{array}{l}\text { Month } \\
\text { Factor }\end{array}$ & $\begin{array}{l}\text { 10-Day } \\
\text { Factor }\end{array}$ \\
\hline \multirow{4}{*}{$\mathrm{CC}$} & Hourly & 0.76 & 0.75 & 0.77 & 0.75 & 0.77 & 0.80 & 0.80 & 0.70 & 0.77 & 0.80 \\
\hline & Daily & 0.79 & 0.78 & 0.90 & 0.78 & 0.90 & 0.79 & 0.76 & 0.90 & 0.76 & 0.90 \\
\hline & 10 days & 0.79 & 0.77 & 1.00 & 0.77 & 1.00 & 0.77 & 0.71 & 1.00 & 0.72 & 1.00 \\
\hline & Monthly & 0.84 & 0.82 & 0.99 & 0.82 & 0.99 & 0.78 & 0.73 & 0.99 & 0.73 & 0.99 \\
\hline \multirow{4}{*}{ BIAS } & Hourly & -0.03 & -0.08 & 0.03 & -0.08 & 0.03 & -0.02 & 0.17 & 0.10 & -0.11 & 0.04 \\
\hline & Daily & 0.04 & -0.05 & -0.01 & -0.04 & 0.00 & 0.46 & 0.04 & 0.00 & 0.04 & 0.00 \\
\hline & 10 days & 0.45 & -0.49 & -0.08 & -0.42 & 0.00 & 4.58 & 0.35 & 0.00 & 0.42 & 0.00 \\
\hline & Monthly & 1.37 & -1.47 & -0.25 & -1.28 & 0.00 & 13.94 & 1.07 & -0.01 & 1.29 & 0.00 \\
\hline \multirow{4}{*}{ MAE } & Hourly & 0.39 & 0.38 & 0.42 & 0.38 & 0.42 & 0.37 & 0.46 & 0.46 & 0.37 & 0.40 \\
\hline & Daily & 2.87 & 2.92 & 2.13 & 2.93 & 2.15 & 3.05 & 3.00 & 2.19 & 2.98 & 2.22 \\
\hline & 10 days & 17.51 & 18.01 & 0.08 & 18.08 & 0.00 & 19.48 & 19.06 & 0.00 & 19.00 & 0.00 \\
\hline & Monthly & 36.35 & 34.34 & 6.28 & 34.36 & 6.02 & 44.19 & 42.41 & 5.74 & 42.00 & 5.97 \\
\hline \multirow{4}{*}{ RMSE } & Hourly & 1.23 & 1.21 & 1.23 & 1.22 & 1.23 & 1.08 & 1.31 & 1.51 & 1.16 & 1.14 \\
\hline & Daily & 7.51 & 7.65 & 5.29 & 7.67 & 5.33 & 7.44 & 7.78 & 5.19 & 7.76 & 5.23 \\
\hline & 10 days & 27.83 & 28.76 & 0.40 & 28.87 & 0.00 & 30.22 & 32.35 & 0.04 & 32.19 & 0.00 \\
\hline & Monthly & 52.64 & 55.16 & 11.75 & 55.34 & 11.53 & 64.90 & 68.99 & 10.05 & 68.47 & 10.23 \\
\hline
\end{tabular}

In summary, we selected precipitation data, which were corrected by RBC-10day as the input data of the BTOP model, refer to them as GSMaP-RBC and IMERG-RBC, respectively. Furthermore, Figure 4 shows the cumulative rainfall for each data source in selected cases. The monthly precipitation of GSMaP-RBC and IMERG-RBC is consistent with the measured precipitation. Furthermore, precipitation is heterogeneous in temporal and spatial scales. The specific effect of the statistical correction method cannot be identified. Moreover, a significant discrepancy still exists from the aspect of a single rainfall event. However, we obtained satisfactory correction results with statistic bias correction methods based on the watershed scale. This shows that from an average point of view, the statistical correction method has considerable effectiveness.

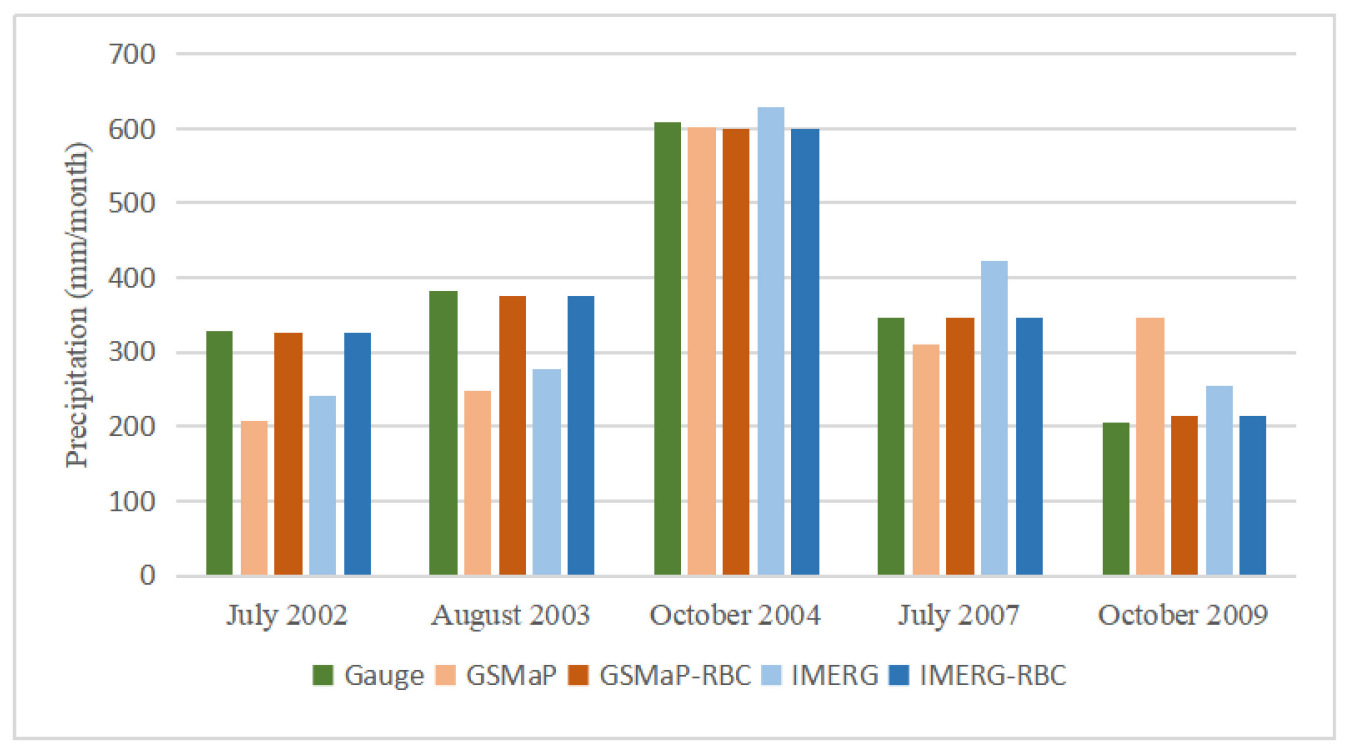

Figure 4. Inter-comparison of cumulative rainfall of different precipitation datasets in five selected months during $2002-2011$. 


\subsubsection{Case Evaluation}

Since the flood discharge simulation focuses on the five cases we selected, it is essential to evaluate the original IMERG and GSMaP and their best-corrected ones (IMERG-RBC, GSMaP-RBC) for the period of each case. Figure 5 shows the Taylor diagram [59] for five flood cases. It can effectively show three indicators (correlation coefficient, normalized standard deviation (NSD), and normalized root mean square deviation (NRMS)) in one chart. Generally, the corrected NRT SPPs have a better performance than the original data. In the case of October 2004, Figure 5c, the original and corrected NRT SPPs show the best agreement with gauge rainfall among five flood cases. In the case of October 2009, Figure 5e, GSMaP performs the worst with a CC around 0.6. The evaluation for these cases could also provide some implications for flood simulation in Section 4.2.
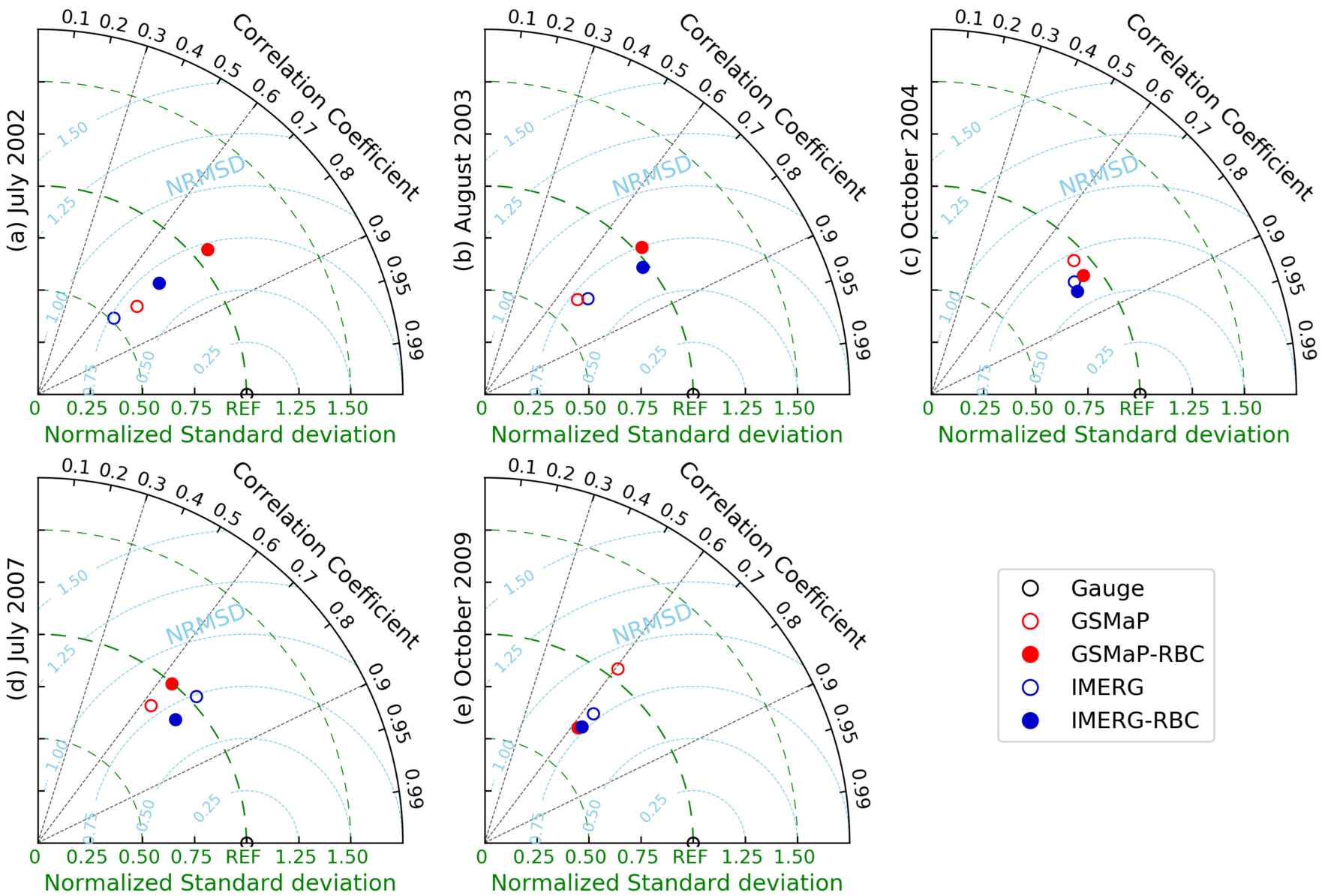

Figure 5. Taylor diagram for the original and best-corrected SPPs of five flood cases. (a)-(e) represent five cases respectively.

\subsection{Flood Discharge Simulation}

Model setup: The BTOP model was run at an hourly time step for five cases (i.e., July 2002, August 2003, October 2004, July 2007, and October 2009). Figure 6 and Table 2 show the hydrographs and evaluation criteria of simulations with five precipitation datasets (i.e., Gauge, GSMaP, IMERG, GSMaP-RBC, IMERG-RBC). We considered that the best-fit parameters of the model are calibrated with well-gauged rainfall input. Therefore, we adopted the parameters calibrated with gauge precipitation to set up the model to simulate discharges with SPPs. The model performed excellently in calibration (October 2004) with an NSE of 0.95 , a CC of 0.98 , a BIAS of $-72.42 \mathrm{~m}^{3} / \mathrm{s}$, and an RMSE of $165.23 \mathrm{~m}^{3} / \mathrm{s}$. The results of validation with gauge rainfall were also satisfactory with NSE of 0.94, 0.94, 0.96, and 0.74 for July 2002, August 2003, July 2007, and October 2009, respectively. It was found that the gauged precipitation performed best among five rainfall data sources. This means 
the BTOP model has the capability to simulate flood discharge with sufficiently accurate rainfall input.

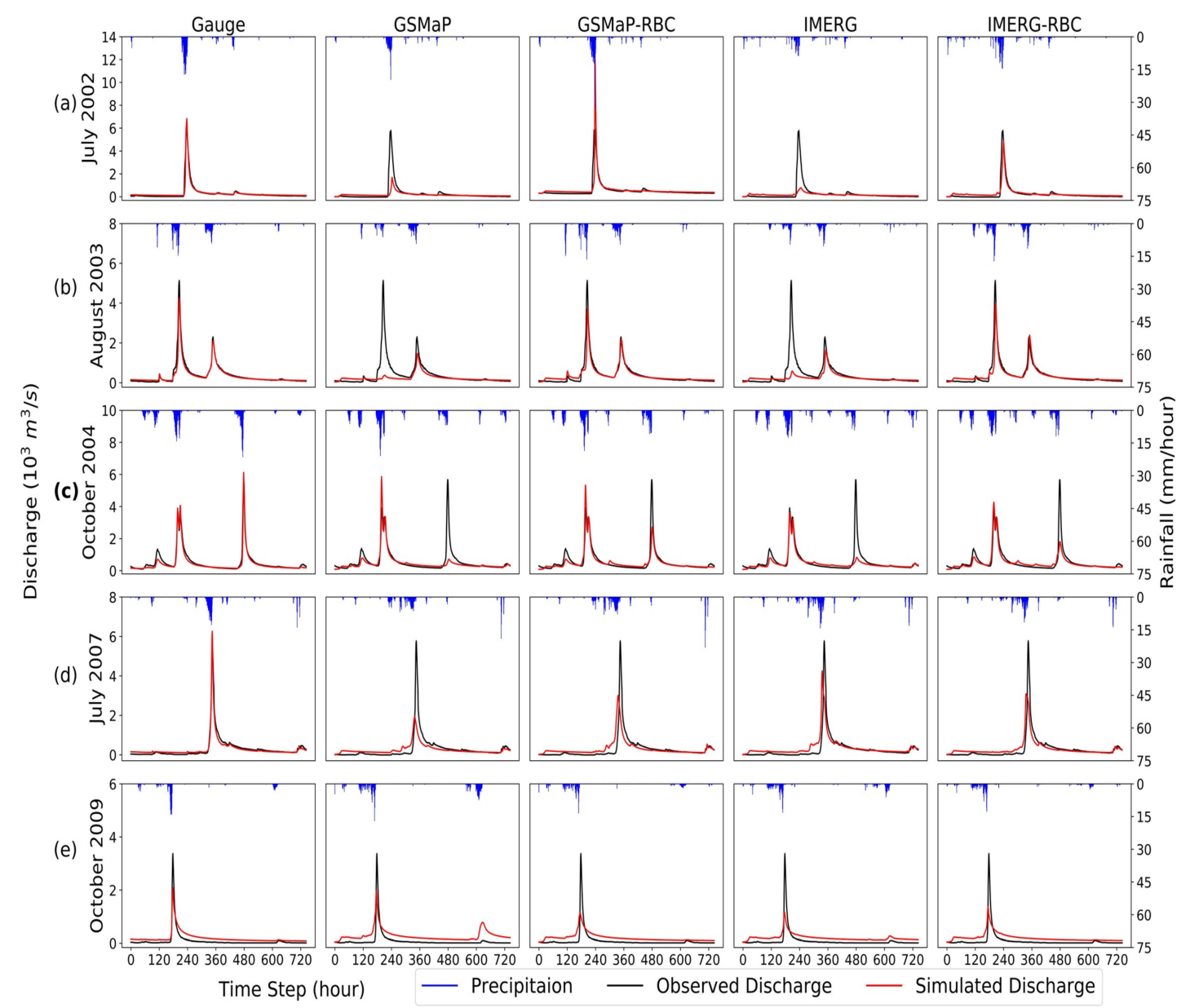

Figure 6. Flood discharge simulation at Kitamatsuno by using five precipitation datasets for five cases. (a)-(e) represent five cases respectively. (c) is the calibration period, while others are the validation period.

Simulation with/without bias correction: The bias-corrected NRT SPPs were used in discharge simulation, and the results were compared with the cases without bias correction. It was found the bias correction significantly improved the performance. In particular, as shown in Table 2, the NSE of runoff simulation with GSMaP-RBC rose from 0.14 to 0.83, CC increased from 0.49 to 0.93 , BIAS decreased from $-152.59 \mathrm{~m}^{3} / \mathrm{s}$ to $-6.32 \mathrm{~m}^{3} / \mathrm{s}$, and RMSE improved from $576.5 \mathrm{~m}^{3} / \mathrm{s}$ to $259.14 \mathrm{~m}^{3} / \mathrm{s}$ in August 2003. Similarly, the NSE of simulation with IMERG-RBC in July 2002 and August 2003 improved from 0.2 to 0.81 and 0.21 to 0.82 , respectively. As shown in Figure 6a-c, the simulated discharges with corrected SPPs have a good agreement with the observed.

In July 2002, the simulated runoff with GSMaP-RBC overestimated the flood peak due to the corrected SPPs enlarged the extreme value of precipitation. Figure $6 \mathrm{~b}$ shows that the simulated discharge of the second flood peak with GSMaP-RBC and IMERG-RBC matches the observed discharge perfectly, even better than gauge simulations. In October 2004, although the results significantly improved after bias correction, there is still a discrepancy of the second flood peak. 
Table 2. Evaluation criteria for flood discharge simulations.

\begin{tabular}{|c|c|c|c|c|c|c|}
\hline Cases & Metrics & Gauge & GSMaP & GSMaP-RBC & IMERG & IMERG-RBC \\
\hline \multirow{4}{*}{ July 2002} & NSE & 0.94 & 0.27 & 0.45 & 0.2 & 0.81 \\
\hline & $C C$ & 0.97 & 0.71 & 0.79 & 0.78 & 0.93 \\
\hline & $B I A S$ & 22.34 & -83.15 & 53.46 & -81.04 & 25.47 \\
\hline & RMSE & 176.02 & 625.87 & 544.55 & 655.3 & 321.45 \\
\hline \multirow{4}{*}{ August 2003} & NSE & 0.94 & 0.14 & 0.83 & 0.21 & 0.82 \\
\hline & $C C$ & 0.99 & 0.49 & 0.93 & 0.56 & 0.92 \\
\hline & $B I A S$ & -31.03 & -152.59 & -6.32 & -139.42 & -13.06 \\
\hline & RMSE & 151.66 & 576.5 & 259.14 & 554.55 & 260.8 \\
\hline October 2004 & NSE & 0.95 & 0.46 & 0.76 & 0.53 & 0.71 \\
\hline \multirow[t]{3}{*}{ Calibration } & CC & 0.98 & 0.7 & 0.88 & 0.75 & 0.85 \\
\hline & $B I A S$ & -72.42 & -88.45 & -43.32 & -98.52 & -57.61 \\
\hline & RMSE & 165.23 & 555.06 & 367.5 & 518.98 & 409.01 \\
\hline \multirow{4}{*}{ July 2007} & NSE & 0.96 & 0.48 & 0.48 & 0.61 & 0.66 \\
\hline & $C C$ & 0.98 & 0.78 & 0.7 & 0.79 & 0.83 \\
\hline & $B I A S$ & -5.98 & -27.22 & 17 & 70.23 & 12.72 \\
\hline & RMSE & 121.71 & 464.15 & 462.39 & 402.04 & 372.09 \\
\hline \multirow{4}{*}{ October 2009} & NSE & 0.74 & 0.25 & 0.37 & 0.41 & 0.41 \\
\hline & $C C$ & 0.95 & 0.77 & 0.75 & 0.87 & 0.78 \\
\hline & $B I A S$ & 100.04 & 190.29 & 115.58 & 114.84 & 113.49 \\
\hline & RMSE & 164.73 & 281.66 & 257.63 & 248.66 & 248.72 \\
\hline
\end{tabular}

However, in the cases of July 2007 and October 2009, the performance of corrected SPPs is not satisfactory. As shown in Figure 6d,e, GSMaP and IMERG overestimated the rainfall before the flood peak and underestimated the actual precipitation event that caused the flood. It caused the simulated discharge to fail to meet the flood peak and also caused the simulated flood peak to move forward. From the aspect of rainfall distribution in these two cases, the NRT SPPs duration is longer than Gauge. It leads the light rainfall heavier and heavy rainfall lighter, and makes the simulated discharge higher than observed when in the low-flow stage and fail to capture the flood peak. Moreover, looking at the rainfall evaluation of five flood cases, Figure $5 \mathrm{~d}$,e, the improvement of original SPPs obviously smaller than other cases. In the view of NSD in these two cases, the corrected SPPs become worse except GSMaP in July 2007. The results show that such statistical bias correction techniques cannot effectively improve all precipitation events when the distribution of SPPs and measured precipitation is inconsistent. Another problem that should be noticed is that in the case of October 2009, even the gauge rainfall cannot capture the flood peak well with an NSE of 0.74. As the hydrological process is a complicated system, the hydrological model has significant uncertainties $[57,60]$. They may come from input data, model parameters, and hydrological processes such as soil moisture changing, evaporation, and runoff process.

More specifically, the scatterplots between observed and simulated discharge are shown in Figure 7. The results with the bias-corrected SPPs show that the high flow part is considerably improved, while the low flow part received new biases. This is related to the fact that satellite precipitation generally overestimates light rain and underestimates heavy one [61]. As we all know, there are uncertainties not only in SPPs but also in hydrologic processing. In this study, we obtained satisfactory results of flood discharge simulation with bias-corrected NRT SPPs. Even though the corrected NRT SPPs still have biases in temporal and spatial, it has the potential to runoff simulation at the basin scale. 


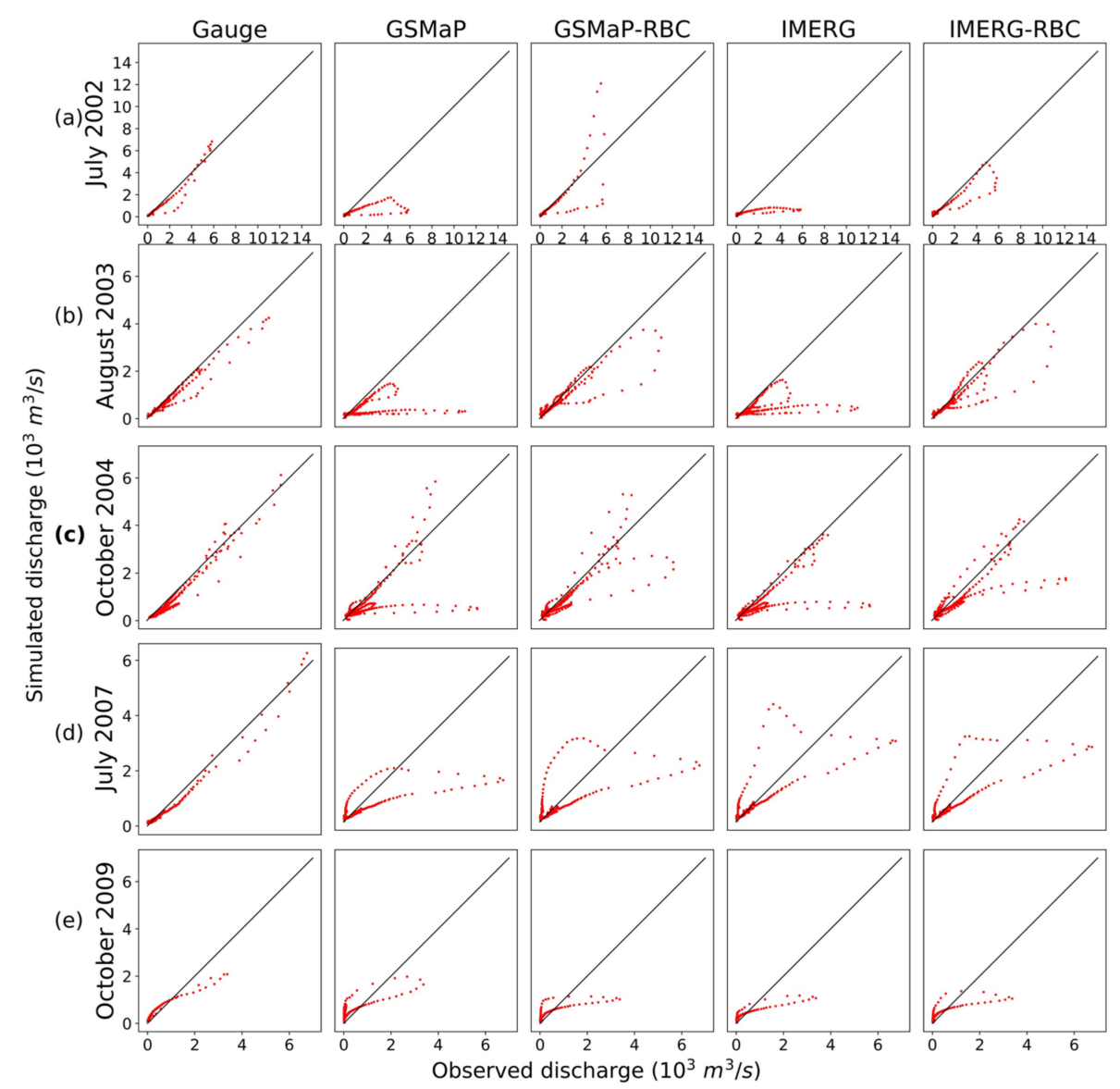

Figure 7. Scatterplots between observed and simulated discharge for five precipitation datasets and five cases. (a)-(e) represent five cases respectively.

\section{Conclusions}

The present work employed two bias correction methods (SMBC, RBC) with two bias factors (month, 10-day) to correct two NRT SPPs (GSMaP-NRT, IMERG-Early) and evaluated both the original and corrected SPPs with comprehensive evaluation indicators. Then, the best-corrected SPPs (GSMaP-RBC, IMERG-RBC) were selected as precipitation in driving the BTOP to simulate flood discharge. The main conclusions are as follows:

(1) Bias correction is necessary and effective for NRT SPPs. All correction methods improved NRT SPPs effectively, of which RBC-10day has the best performance. However, for the heterogeneity of precipitation in time and space, the statistical correction has certain limitations. Therefore, it is necessary to introduce the dynamic bias correction approach utilizing available ground rainfall data at higher temporal scales (e.g., daily) in future work.

(2) The consistency of SPPs with gauge rainfall improves as the spatial and temporal scale increases. It is significant for studies on a watershed scale or large scale. This principle is also applicable to runoff simulation of watersheds.

(3) The GSMaP-NRT and IMERG-Early show a considerable potential to simulate flood discharge in the Fuji River. Although precipitation and hydrological processes are heterogeneous in time and space, the BTOP runoff simulation results at hourly steps are satisfactory using the corrected GSMaP-NRT and IMERG-Early as forcing precipitation. At the same time, it suggests a high potential for the application of NRT SPPs in many data-sparse watersheds in the world.

(4) The present work applied a robust hydrological model in the Fuji River basin. Moreover, a comprehensive evaluation system has been introduced. According to this paper, the corrected SPPs and hydrological simulation show good results with sufficient rainfall stations. Future work will focus on the impacts of the pattern of the gauge network. 
We will take the Fuji River basin as a case to study the gauge network's impact on bias correction of SPPs and hydrological simulation. To further figure out how to improve the hydrological efficiency in the case of a limited gauge network.

In general, the results showed that the NRT SPPs could be valuable alternative data for flood forecasting in other river basins and can provide references for applying NRT SPPs in other basins, particularly in poor- or un-gauged river basins for real-time flood simulation, flood early warning, even flood extent mapping for disaster assessment and management.

Author Contributions: Conceptualization, L.Z., K.T. and T.K.; methodology, L.Z. and M.R.; software, L.Z. and H.S.; formal analysis, L.Z., M.R., K.T., T.K. and H.S.; writing—original draft preparation, L.Z.; writing-review and editing, L.Z., M.R., K.T., T.K. and T.A.; visualization, L.Z. and H.S.; supervision, K.T., T.K. and T.A.; funding acquisition, T.A. and L.Z. All authors have read and agreed to the published version of the manuscript.

Funding: This research was supported by Regional Innovation Cooperation Program from the Science\& Technology Department of Sichuan Province, grant number 2020YFQ0013 and China Scholarship Council, grant number 201806240035.

Institutional Review Board Statement: Not applicable.

Informed Consent Statement: Not applicable.

Data Availability Statement: The study did not report any data.

Acknowledgments: The authors thank the anonymous referees for their valuable comments and suggestions.

Conflicts of Interest: The authors declare no conflict of interest.

\section{References}

1. Zhang, K.; Xue, X.; Hong, Y.; Gourley, J.J.; Lu, N.; Wan, Z.; Hong, Z.; Wooten, R. iCRESTRIGRS: A coupled modeling system for cascading flood-landslide disaster forecasting. Hydrol. Earth Syst. Sci. 2016, 20, 5035-5048. [CrossRef]

2. Alfieri, L.; Pappenberger, F.; Wetterhall, F.; Haiden, T.; Richardson, D.; Salamon, P. Evaluation of ensemble streamflow predictions in Europe. J. Hydrol. 2014, 517, 913-922. [CrossRef]

3. Gebregiorgis, A.S.; Hossain, F. Understanding the dependence of satellite rainfall uncertainty on topography and climate for hydrologic model simulation. IEEE Trans. Geosci. Remote 2013, 51, 704-718. [CrossRef]

4. Marani, M. Non-power-law-scale properties of rainfall in space and time. Water Resour. Res. 2005, 41. [CrossRef]

5. Renard, B.; Kavetski, D.; Kuczera, G.; Thyer, M.; Franks, S.W. Understanding predictive uncertainty in hydrologic modeling: The challenge of identifying input and structural errors. Water Resour Res. 2010, 46. [CrossRef]

6. Li, D.; Christakos, G.; Ding, X.; Wu, J. Adequacy of TRMM satellite rainfall data in driving the SWAT modeling of Tiaoxi catchment (Taihu lake basin, China). J. Hydrol. 2018, 556, 1139-1152. [CrossRef]

7. Xue, X.; Hong, Y.; Limaye, A.S.; Gourley, J.J.; Huffman, G.J.; Khan, S.I.; Dorji, C.; Chen, S. Statistical and hydrological evaluation of TRMM-based Multi-satellite Precipitation Analysis over the Wangchu Basin of Bhutan: Are the latest satellite precipitation products 3B42V7 ready for use in ungauged basins? J. Hydrol. 2013, 499, 91-99. [CrossRef]

8. Huffman, G.J.; Bolvin, D.T.; Nelkin, E.J.; Wolff, D.B.; Adler, R.F.; Gu, G.; Hong, Y.; Bowman, K.P.; Stocker, E.F. The TRMM multisatellite precipitation analysis (TMPA): Quasi-global, multiyear, combined-sensor precipitation estimates at fine scales. J. Hydrometeorol. 2007, 8, 38-55. [CrossRef]

9. Sorooshian, S.; Hsu, K.; Gao, X.; Gupta, H.V.; Imam, B.; Braithwaite, D. Evaluation of PERSIANN system satellite-based estimates of tropical rainfall. B. Am. Meteorol. Soc. 2000, 81, 2035-2046. [CrossRef]

10. Joyce, R.J.; Janowiak, J.E.; Arkin, P.A.; Xie, P. CMORPH: A method that produces global precipitation estimates from passive microwave and infrared data at high spatial and temporal resolution. J. Hydrometeorol. 2004, 5, 487-503. [CrossRef]

11. Ushio, T.; Sasashige, K.; Kubota, T.; Shige, S.; Okamoto, K.; Aonashi, K.; Inoue, T.; Takahashi, N.; Iguchi, T.; Kachi, M.; et al. A kalman filter approach to the global satellite mapping of precipitation (GSMaP) from combined passive microwave and infrared radiometric data. J. Meteorol. Soc. Jpn. 2009, 87, 137-151. [CrossRef]

12. Kubota, T.; Shige, S.; Hashizume, H.; Aonashi, K.; Takahashi, N.; Seto, S.; Hirose, M.; Takayabu, Y.N.; Ushio, T.; Nakagawa, K.; et al. Global precipitation map using satellite-borne microwave radiometers by the GSMaP project: Production and validation. IEEE Trans. Geosci. Remote 2007, 45, 2259-2275. [CrossRef]

13. IMERG: Integrated Multi-Satellite Retrievals for GPM I NASA Global Precipitation Measurement Mission. Available online: https://gpm.nasa.gov/data/imerg (accessed on 10 December 2020).

14. Tekeli, A.E.; Fouli, H. Evaluation of TRMM satellite-based precipitation indexes for flood forecasting over Riyadh City, Saudi Arabia. J. Hydrol. 2016, 541, 471-479. [CrossRef] 
15. Koriche, S.A.; Rientjes, T.H.M. Application of satellite products and hydrological modelling for flood early warning. Phys. Chem. Earth Parts A/B/C 2016, 93, 12-23. [CrossRef]

16. Wu, H.; Adler, R.F.; Tian, Y.; Huffman, G.J.; Li, H.; Wang, J. Real-time global flood estimation using satellite-based precipitation and a coupled land surface and routing model. Water Resour. Res. 2014, 50, 2693-2717. [CrossRef]

17. Lai, C.; Zhong, R.; Wang, Z.; Wu, X.; Chen, X.; Wang, P.; Lian, Y. Monitoring hydrological drought using long-term satellite-based precipitation data. Sci. Total Environ. 2019, 649, 1198-1208. [CrossRef]

18. Yong, B.; Chen, B.; Gourley, J.J.; Ren, L.; Hong, Y.; Chen, X.; Wang, W.; Chen, S.; Gong, L. Intercomparison of the Version-6 and Version-7 TMPA precipitation products over high and low latitudes basins with independent gauge networks: Is the newer version better in both real-time and post-real-time analysis for water resources and hydrologic extremes? J. Hydrol. 2014, 508, 77-87. [CrossRef]

19. Chen, S.; Hong, Y.; Gourley, J.J.; Huffman, G.J.; Tian, Y.; Cao, Q.; Yong, B.; Kirstetter, P.; Hu, J.; Hardy, J.; et al. Evaluation of the successive V6 and V7 TRMM multisatellite precipitation analysis over the Continental United States. Water Resour. Res. 2013, 49, 8174-8186. [CrossRef]

20. Lo Conti, F.; Hsu, K.; Noto, L.V.; Sorooshian, S. Evaluation and comparison of satellite precipitation estimates with reference to a local area in the Mediterranean Sea. Atmos. Res. 2014, 138, 189-204. [CrossRef]

21. Belabid, N.; Zhao, F.; Brocca, L.; Huang, Y.; Tan, Y. Near-real-time flood forecasting based on satellite precipitation products. Remote Sens. 2019, 11, 252. [CrossRef]

22. Shi, J.; Yuan, F.; Shi, C.; Zhao, C.; Zhang, L.; Ren, L.; Zhu, Y.; Jiang, S.; Liu, Y. Statistical evaluation of the latest GPM-era IMERG and GSMaP satellite precipitation products in the Yellow river source region. Water 2020, 12, 1006. [CrossRef]

23. Yuan, F.; Zhang, L.; Soe, K.; Ren, L.; Zhao, C.; Zhu, Y.; Jiang, S.; Liu, Y. Applications of TRMM- and GPM-era multiple-satellite precipitation products for flood simulations at sub-daily scales in a sparsely gauged watershed in myanmar. Remote Sens. 2019, 11, 140. [CrossRef]

24. Anjum, M.N.; Ding, Y.; Shangguan, D.; Ijaz, M.W.; Zhang, S.; Ushio, T. Evaluation of high-resolution satellite-based real-time and post-real-time precipitation estimates during 2010 extreme flood event in Swat river basin, Hindukush region. Adv. Meteorol. 2016, 2016, 2604980. [CrossRef]

25. Ren, P.; Li, J.; Feng, P.; Guo, Y.; Ma, Q. Evaluation of multiple satellite precipitation products and their use in hydrological modelling over the Luanhe river basin, China. Water 2018, 10, 677. [CrossRef]

26. Behrangi, A.; Khakbaz, B.; Jaw, T.C.; Aghakouchak, A.; Hsu, K.; Sorooshian, S. Hydrologic evaluation of satellite precipitation products over a mid-size basin. J. Hydrol. 2011, 397, 225-237. [CrossRef]

27. Shah, R.D.; Mishra, V. Development of an experimental near-real-time drought monitor for India. J. Hydrometeorol. 2015, 16, 327-345. [CrossRef]

28. Borga, M.; Tonelli, F.; Moore, R.J.; Andrieu, H. Long-term assessment of bias adjustment in radar rainfall estimation. Water Resour. Res. 2002, 38, 1-8. [CrossRef]

29. Xie, P.; Xiong, A. A conceptual model for constructing high-resolution gauge-satellite merged precipitation analyses. J. Geophys. Res. Space Phys. 2011, 116. [CrossRef]

30. Ringard, J.; Seyler, F.; Linguet, L. A Quantile mapping bias correction method based on hydroclimatic classification of the Guiana Shield. Sensors 2017, 17, 1413. [CrossRef]

31. Tian, Y.; Peters-Lidard, C.D.; Eylander, J.B. Real-time bias reduction for satellite-based precipitation estimates. J. Hydrometeorol. 2010, 11, 1275-1285. [CrossRef]

32. Bhatti, H.; Rientjes, T.; Haile, A.; Habib, E.; Verhoef, W. Evaluation of bias correction method for satellite-based rainfall data. Sensors 2016, 16, 884. [CrossRef] [PubMed]

33. Mastrantonas, N.; Bhattacharya, B.; Shibuo, Y.; Rasmy, M.; Espinoza-Dávalos, G.; Solomatine, D. Evaluating the benefits of merging near-real-time satellite precipitation products: A case study in the Kinu basin region, Japan. J. Hydrometeorol. 2019, 20, 1213-1233. [CrossRef]

34. Kumar, A.; Ramsankaran, R.; Brocca, L.; Munoz-Arriola, F. A machine learning approach for improving near-real-time satellitebased rainfall estimates by integrating soil moisture. Remote Sens 2019, 11, 2221. [CrossRef]

35. Bharti, V.; Singh, C. Evaluation of error in TRMM 3B42V7 precipitation estimates over the Himalayan region. J. Geophys. Res. Space Phys. 2015, 120, 12458-12473. [CrossRef]

36. Wanders, N.; Pan, M.; Wood, E.F. Correction of real-time satellite precipitation with multi-sensor satellite observations of land surface variables. Remote Sens. Environ. 2015, 160, 206-221. [CrossRef]

37. Awaka, J.; Le, M.; Chandrasekar, V.; Yoshida, N.; Higashiuwatoko, T.; Kubota, T.; Iguchi, T. Rain Type Classification Algorithm Module for GPM Dual-Frequency Precipitation Radar. J. Atmos Ocean Tech. 2016, 33, 1887-1898. [CrossRef]

38. Shrestha, S.; Kazama, F. An export coefficient modeling approach to estimate organic matter and nutrient loadings from point and non point sources into the Fuji river, Japan. Proc. Symp. Glob. Environ. 2006, 14, 21-26. [CrossRef]

39. JAXA Global Rainfall Watch. Available online: https:/ / sharaku.eorc.jaxa.jp/GSMaP/ (accessed on 10 December 2020).

40. NASA Goddard Earth Sciences (GES) Data and Information Services Center (DISC). Available online: https:/ / disc.gsfc.nasa.gov/ (accessed on 10 December 2020).

41. LP DAAC-SRTMGL3. Available online: https://lpdaac.usgs.gov/products/srtmgl3v003/ (accessed on 10 December 2020).

42. LP DAAC-MCD12Q1. Available online: https://lpdaac.usgs.gov/products/mcd12q1v006/ (accessed on 10 December 2020). 
43. FAO Digital Soil Map of the World (DSMW). Available online: http://www.fao.org/land-water/land/land-governance/landresources-planning-toolbox/category/details/en/c/1026564/ (accessed on 10 December 2020).

44. NOAA Climate Data Record (CDR) of Normalized Difference Vegetation Index (NDVI), Version 4 (Version Superseded). Available online: https:/ / www.ncei.noaa.gov/access/metadata/landing-page/bin/iso?id=gov.noaa.ncdc:C00813 (accessed on 10 December 2020).

45. Harris, I.; Osborn, T.J.; Jones, P.; Lister, D. Version 4 of the CRU TS monthly high-resolution gridded multivariate climate dataset. Sci. Data 2020, 7. [CrossRef]

46. Goly, A.; Teegavarapu, R.S.V. Optimization and variants of quantile-based methods for bias corrections of statistically downscaled precipitation data. J. Hydrol. Eng. 2020, 25, 4020027. [CrossRef]

47. Gentile, M.; Courbin, F.; Meylan, G. Interpolating point spread function anisotropy. Astron. Astrophys. 2013, 549, A1. [CrossRef]

48. Azpurua, M.A.; Ramos, K.D. A comparison of spatial interpolation methods for estimation of average electromagnetic field magnitude. Prog. Electromagn. Res. M 2010, 14, 135-145. [CrossRef]

49. Takeuchi, K.; Ao, T.; Ishidaira, H. Introduction of block-wise use of TOPMODEL and Muskingum-Cunge method for the hydroenvironmental simulation of a large ungauged basin. Hydrol. Sci. J. 1999, 44, 633-646. [CrossRef]

50. Takeuchi, K.; Hapuarachchi, P.; Zhou, M.; Ishidaira, H.; Magome, J. A BTOP model to extend TOPMODEL for distributed hydrological simulation of large basins. Hydrol. Process. 2008, 22, 3236-3251. [CrossRef]

51. Ao, T.; Ishidaira, H.; Takeuchi, K. Study of distributed runoff simulation model based on block type TOPMODEL and muskingumcunge method. Proc. Hydr. Eng. 1999, 43, 7-12. [CrossRef]

52. Ao, T.; Ishidaira, H.; Takeuchi, K.; Kiem, A.S.; Yoshitari, J.; Fukami, K.; Magome, J. Relating BTOPMC model parameters to physical features of MOPEX basins. J. Hydrol. 2006, 320, 84-102. [CrossRef]

53. Beven, K.J.; Kirkby, M.J. A physically based, variable contributing area model of basin hydrology. Hydrol. Sci. Bull. 1979, 1, 43-69. [CrossRef]

54. Magome, J.; Gusyev, M.A.; Hasegawa, A.; Takeuchi, K. River discharge simulation of a distributed hydrological model on global scale for the hazard quantification. In Proceedings of the 21st International Congress on Modelling and Simulation (MODSIM2015), Broadbeach, QLD, Australia, 29 December 2015; pp. 1593-1599.

55. Gusyev, M.; Gädeke, A.; Cullmann, J.; Magome, J.; Sugiura, A.; Sawano, H.; Takeuchi, K. Connecting global- and local-scale flood risk assessment: A case study of the Rhine River basin flood hazard. J. Flood Risk Manag. 2016, 9, 343-354. [CrossRef]

56. Zhang, H.; Ao, T.; Gusyev, M.; Ishidaira, H.; Magome, J.; Takeuchi, K. Distributed source pollutant transport module based on BTOPMC: A case study of the Laixi River basin in the Sichuan province of southwest China. Proc. Int. Assoc. Hydrol. Sci. 2018, 379, 323-333. [CrossRef]

57. Liu, L.; Zhou, L.; Li, X.; Chen, T.; Ao, T. Screening and optimizing the sensitive parameters of BTOPMC model based on UQ-PyL software: Case study of a flood event in the Fuji river basin, Japan. J. Hydrol. Eng. 2020, 25. [CrossRef]

58. Zhou, M.C.; Ishidaira, H.; Hapuarachchi, H.P.; Magome, J.; Kiem, A.S.; Takeuchi, K. Estimating potential evapotranspiration using Shuttleworth-Wallace model and NOAA-AVHRR NDVI data to feed a distributed hydrological model over the Mekong River basin. J. Hydrol. 2006, 327, 151-173. [CrossRef]

59. Taylor, K.E. Summarizing multiple aspects of model performance in a single diagram. J. Geophys. Res. Atmos. 2001, 106, 7183-7192. [CrossRef]

60. Bastola, S.; Murphy, C.; Sweeney, J. The role of hydrological modelling uncertainties in climate change impact assessments of Irish river catchments. Adv. Water Resour. 2011, 34, 562-576. [CrossRef]

61. Tong, K.; Su, F.; Yang, D.; Hao, Z. Evaluation of satellite precipitation retrievals and their potential utilities in hydrologic modeling over the Tibetan Plateau. J. Hydrol. 2014, 519, 423-437. [CrossRef] 